\title{
COVID-19 pandemic and mental health of universities' students in Africa: a systematic review
}

Diane Laure Meli Tiwa ${ }^{1}$, Dominic Leandry Angong Wouna ${ }^{1}$, and Francky Teddy Endomba 1

${ }^{1}$ Affiliation not available

August 23, 2021

\begin{tabular}{|c|c|c|c|c|c|c|c|c|c|c|c|}
\hline Study & Q1 & Q2 & Q3 & Q4 & Q5 & Q6 & Q7 & Q8 & Q9 & Q10 & 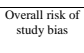 \\
\hline $\begin{array}{l}\text { Abas et al. } \\
2021\end{array}$ & Low Risk & High Risk & Low Risk & High Risk & $\begin{array}{l}=1=\text { Low Ris } \\
\text { High Risk }\end{array}$ & \begin{tabular}{|l|} 
No $=0=0=$ Hig \\
Low Risk
\end{tabular} & \begin{tabular}{|l} 
Risk \\
Low Risk
\end{tabular} & Low Risk & \begin{tabular}{|l} 
Low Risk \\
\end{tabular} & \begin{tabular}{|l} 
Low Risk \\
\end{tabular} & $\begin{array}{l}\text { Moderate Risk } \\
\text { Scrof }\end{array}$ \\
\hline $\begin{array}{l}\text { Awooke et al. } \\
2021\end{array}$ & High Risk & High Risk & High Risk & Low Risk & High Risk & Low Risk & Low Risk & Low Risk & Low Risk & Low Risk & $\begin{array}{l}\text { Moderate Risk } \\
\text { (Score of } 6 \text { ) }\end{array}$ \\
\hline $\begin{array}{l}\text { Aylie et al. } \\
2020\end{array}$ & Low Risk & High Risk & Low Risk & Low Risk & Low Risk & Low Risk & Low Risk & Low Risk & Low Risk & Low Risk & $\begin{array}{l}\begin{array}{l}\text { Low Risk } \\
\text { (Score of } 9)\end{array} \\
\end{array}$ \\
\hline $\begin{array}{l}\text { Davis et al. } \\
2021\end{array}$ & Low Risk & High Risk & High Risk & High Risk & High Risk & Low Risk & Low Risk & Low Risk & Low Risk & Low Risk & $\begin{array}{l}\text { Moderate Risk } \\
\text { (Score of } 6 \text { ) }\end{array}$ \\
\hline $\begin{array}{l}\text { Ellhadi et al. } \\
2021\end{array}$ & Low Risk & High Risk & High Risk & High Risk & High Risk & \begin{tabular}{|l|} 
Low Risk \\
\end{tabular} & Low Risk & Low Risk & \begin{tabular}{|l|} 
Low Risk \\
\end{tabular} & \begin{tabular}{|l} 
Low Risk \\
\end{tabular} & $\begin{array}{l}\text { Moderate Risk } \\
\text { (Score of } 6 \text { ) }\end{array}$ \\
\hline $\begin{array}{l}\text { El-Monshed et } \\
\text { al. } 2021\end{array}$ & Low Risk & High Risk & High Risk & High Risk & High Risk & Low Risk & Low Risk & Low Risk & Low Risk & Low Risk & $\begin{array}{l}\begin{array}{l}\text { Moderate Risk } \\
\text { (Score of 6) }\end{array} \\
\end{array}$ \\
\hline $\begin{array}{l}\text { Essangri et al. } \\
2021\end{array}$ & Low Risk & Low Risk & Low Risk & High Risk & High Risk & Low Risk & Low Risk & Low Risk & Low Risk & Low Risk & $\begin{array}{l}\text { Low Rik } \\
\text { (Score of } 8)\end{array}$ \\
\hline $\begin{array}{l}\text { Ghazawy et al. } \\
2020\end{array}$ & Low Risk & High Risk & High Risk & High Risk & High Risk & Low Risk & Low Risk & Low Risk & Low Risk & Low Risk & $\begin{array}{l}\text { Moderate Risk } \\
\text { (Score of } 6 \text { ) }\end{array}$ \\
\hline 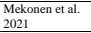 & Low Risk & Low Risk & Low Risk & Low Risk & High Risk & Low Risk & Low Risk & Low Risk & Low Risk & Low Risk & $\begin{array}{l}\text { Low Risk } \\
\text { (Score of 9) }\end{array}$ \\
\hline $\begin{array}{l}\text { Rahali et al. } \\
2020\end{array}$ & High Risk & High Risk & High Risk & High Risk & High Risk & High Risk & Low Risk & Low Risk & \begin{tabular}{|l} 
Low Risk \\
\end{tabular} & Low Risk & $\begin{array}{l}\text { High Risk } \\
\text { (Score of 4) }\end{array}$ \\
\hline $\begin{array}{l}\text { Saguem et al. } \\
2021\end{array}$ & Low Risk & High Risk & \begin{tabular}{|l|} 
Low Risk \\
\end{tabular} & High Risk & High Risk & Low Risk & Low Risk & Low Risk & Low Risk & $\begin{array}{l}\text { Low Risk } \\
\end{array}$ & $\begin{array}{l}\text { Moderate Risk } \\
\text { (Score of 7) }\end{array}$ \\
\hline 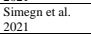 & Low Risk & Low Risk & Low Risk & Low Risk & High Risk & Low Risk & Low Risk & Low Risk & Low Risk & \begin{tabular}{|l} 
Low Risk \\
\end{tabular} & $\begin{array}{l}\text { Low Risk } \\
\text { (Score of } 9 \text { ) }\end{array}$ \\
\hline \multicolumn{12}{|c|}{ 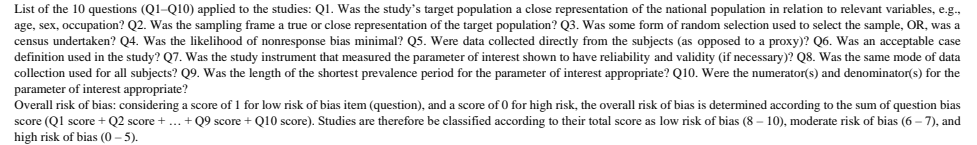 } \\
\hline
\end{tabular}

Figure 1: This is a caption 


\begin{tabular}{|c|c|c|c|c|c|c|}
\hline 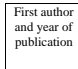 & $\begin{array}{c}\text { Study } \\
\text { characteristics } \\
\text { (country, setting, } \\
\text { design, period) }\end{array}$ & $\begin{array}{l}\text { Sampling method } \\
\text { and Sample size } \\
\text { (overall, for male } \\
\text { and/or female) }\end{array}$ & $\begin{array}{l}\text { Participants' } \\
\text { characteristic age } \\
\text { being in years) }\end{array}$ & $\begin{array}{l}\text { Mental health issues } \\
\text { assesese, with tool sand } \\
\text { cut-off used }\end{array}$ & $\begin{array}{l}\begin{array}{l}\text { Frequencies of mental health } \\
\text { issues assessed in the study }\end{array} \\
\end{array}$ & $\begin{array}{c}\text { Reported factors of mental health issues } \\
\text { assessed }\end{array}$ \\
\hline $\begin{array}{l}\text { Abas } \\
\text { etal } \\
2021\end{array}$ & \begin{tabular}{|l|} 
Sudan, 21 \\
universities, \\
online cross- \\
sectional study, \\
May 2020 \\
(during the $1^{*}$ \\
COVID-19 wave)
\end{tabular} & \begin{tabular}{|l|l|} 
Probabililistic \\
(Stratified random \\
sampling, total \\
sample size of 478 \\
(34t males and 134 \\
females)
\end{tabular} & $\begin{array}{l}\text { Unspecified } \\
\text { specialties, mean } \\
\text { age of } 21.6 \pm 2.8, \\
\text { upper extreme of } \\
39 \text { and lower one } \\
\text { not reported }\end{array}$ & $\begin{array}{l}\text { Anxiety. } \\
\text { Beck Anxiety Inventory/ } \\
\text { BAL. Scores of } 0-21=\text { low } \\
\text { anxiety } 22-35=\text { moderate } \\
\text { anxiety } \geq 36=\text { potentially } \\
\text { concerning level of anxiety }\end{array}$ & $\begin{array}{l}\text { Of the study sample, } 75.1 \% \\
\text { had low anxiety } 1.5 \% \text { had } \\
\text { moderate anxiety and } 9.4 \% \\
\text { had potentially concerning } \\
\text { level of anxiety }\end{array}$ & $\begin{array}{l}\text { Not complying with the curfew measures, } \\
\text { and the preventive etiquette of covering } \\
\text { mouth while coughing or sneezing were } \\
\text { associated with potentially concerning } \\
\text { levels of anxiety while experiencing fever, } \\
\text { sore throat and myalgia were associated } \\
\text { with moderate anxiety }\end{array}$ \\
\hline 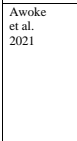 & \begin{tabular}{|l|} 
Ethiopia, one \\
university, cross- \\
sectional email- \\
based survey, \\
August to \\
September 5 , \\
2020
\end{tabular} & 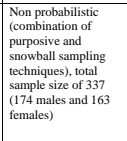 & $\begin{array}{l}\text { Health science } \\
\text { students, mean age } \\
\text { of } 22.8 \pm 1.8 \text { age } \\
\text { range not reported }\end{array}$ & \begin{tabular}{|l|} 
Stress. \\
Pereceived stress scale \\
(PSS)-10. Scores $\geq 25=$ \\
high perceived stress, and \\
scores $<25=$ low \\
perceived stress
\end{tabular} & $\begin{array}{l}\text { Of the study sample, } 35.9 \% \\
\text { reported high perceived } \\
\text { stress levels while } 64.1 \% \\
\text { reportede } \\
\text { low perceived stress }\end{array}$ & 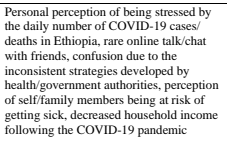 \\
\hline $\begin{array}{l}\text { Aylie } \\
\text { etal. } \\
2020\end{array}$ & 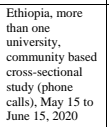 & 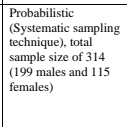 & \begin{tabular}{|l|} 
Unspecified \\
ssecialties, $22.8 \pm$ \\
2.8, lower extreme \\
of 18 years, upper \\
extreme not \\
reported
\end{tabular} & \begin{tabular}{|l} 
Depression, anxiety, stress \\
(DAS). \\
DAS Scale (DASS) with \\
subscales for depression, \\
anxiety, stress, and \\
respective cut-offs of $\geq 10$, \\
$\geq 0$ and $\geq 15$
\end{tabular} & 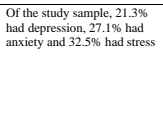 & 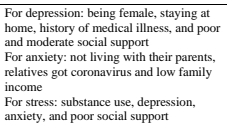 \\
\hline \begin{tabular}{|l}
$\begin{array}{l}\text { Davis } \\
\text { etal. } \\
2021\end{array}$ \\
2021
\end{tabular} & $\begin{array}{l}\text { Liberia, one } \\
\text { university, cross- } \\
\text { sectional email- } \\
\text { based survey, } \\
\text { July } 1 \text { to October } \\
30.2020\end{array}$ & $\begin{array}{l}\begin{array}{l}\text { Non probabilistic } \\
\text { (Purposive } \\
\text { sampling, total } \\
\text { sample size of } 103 \\
\text { (63 males and } 40 \\
\text { females) }\end{array} \\
\end{array}$ & \begin{tabular}{|l|} 
Pharmacy and \\
medical students, \\
mmedian age of 29 \\
linterquartile range \\
of 26.3, , gage $\geq 18$, \\
no range reported
\end{tabular} & \begin{tabular}{|l|} 
Depression. \\
Patient Health \\
Questionanare with 8 items \\
(PHQ-8). Positive \\
depression screening if $\geq$ \\
10
\end{tabular} & \begin{tabular}{|l|}
$\begin{array}{l}\text { of the study sample, } 19.4 \% \\
\text { had a positive depression } \\
\text { screen }\end{array}$ \\
\end{tabular} & $\begin{array}{l}\text { Concerns about the health of household } \\
\text { members, household finances, and sharing } \\
\text { a house with more people }\end{array}$ \\
\hline
\end{tabular}

Figure 2: This is a caption 
Table 2: Data extraction form

\begin{tabular}{|c|c|}
\hline \multicolumn{2}{|l|}{ BIBLIOMETRIC PROFILE } \\
\hline \multicolumn{2}{|l|}{ Family name of the first author } \\
\hline \multicolumn{2}{|l|}{ Year of publication } \\
\hline \multicolumn{2}{|c|}{\begin{tabular}{l|l} 
Journal of publication & \\
\end{tabular}} \\
\hline \multicolumn{2}{|l|}{ STUDY AND PARTICIPANTS CHARACTERISTICS } \\
\hline \multicolumn{2}{|c|}{\begin{tabular}{|l|l} 
Country of the study & \\
\end{tabular}} \\
\hline Study design & $\begin{array}{l}\text { 1. Cross-sectional } \\
\text { 2. Cohort study (baseline data) } \\
\text { 3. Case control study } \\
\text { 4. Unclear study design } \\
\end{array}$ \\
\hline \multicolumn{2}{|l|}{ Study period } \\
\hline Study setting & $\begin{array}{l}\text { 1. One Faculty } \\
\text { 2. More than one Faculty of one university } \\
\text { 3. More than one university }\end{array}$ \\
\hline \multicolumn{2}{|l|}{ Subtype of university students } \\
\hline Sampling method & $\begin{array}{ll}\text { 1. } & \text { Probabilistic (to specify) } \\
\text { 2. } & \text { Non probabilistic (to specify) } \\
\text { 3. } & \text { Unclear }\end{array}$ \\
\hline Minimal sample size & $\begin{array}{l}\text { 1. Calculated AND attained } \\
\text { 2. Calculated BUT NOT attained } \\
\text { 3. Not calculated }\end{array}$ \\
\hline Type of data collection process & $\begin{array}{l}\text { 1. Direct (paper version of data collection form) } \\
\text { 2. Social media (WhatsApp, Facebook, etc.) } \\
\text { 3. E-mail } \\
\text { 4. Other (to precise) }\end{array}$ \\
\hline \multicolumn{2}{|l|}{$\begin{array}{l}\text { Mean or median age } \\
\text { (If not reported, please write NR.) }\end{array}$} \\
\hline \multicolumn{2}{|l|}{$\begin{array}{l}\text { Inferior limit of age in years (as reported in the } \\
\text { results or in the selection criteria) } \\
\text { (If not reported, please write NR.) }\end{array}$} \\
\hline \multicolumn{2}{|l|}{$\begin{array}{l}\text { Superior limit of age in years (as reported in the } \\
\text { results or in the selection criteria) } \\
\text { (If not reported, please write NR.) }\end{array}$} \\
\hline \multicolumn{2}{|l|}{ KEY DATA EXTRACTION SECTION } \\
\hline \multicolumn{2}{|l|}{ Label of the studied condition } \\
\hline \multicolumn{2}{|l|}{$\begin{array}{l}\text { Tool or method used to conclude } \\
\text { (Write NR if not reported) }\end{array}$} \\
\hline \multicolumn{2}{|l|}{$\begin{array}{l}\text { Cut-off used } \\
\text { (Write NR if not reported) }\end{array}$} \\
\hline \multicolumn{2}{|l|}{ Total sample size } \\
\hline \multicolumn{2}{|l|}{$\begin{array}{l}\text { Total number of male participants } \\
\text { (Write NR if not reported) }\end{array}$} \\
\hline \multicolumn{2}{|l|}{$\begin{array}{l}\text { Total number of female participants } \\
\text { (Write NR if not reported) }\end{array}$} \\
\hline \multicolumn{2}{|l|}{$\begin{array}{l}\text { Frequency of the studied condition (with details } \\
\text { according to the severity) }\end{array}$} \\
\hline $\begin{array}{l}\text { Associated or risk factors of the studied } \\
\text { condition } \\
\text { (Write NR if not reported) }\end{array}$ & \\
\hline
\end{tabular}

Figure 3: This is a caption 
Table 1: Search strategy used, adapted to each of our databases

\begin{tabular}{|c|c|c|}
\hline Database & Search strategy & Last search date \\
\hline PubMed & 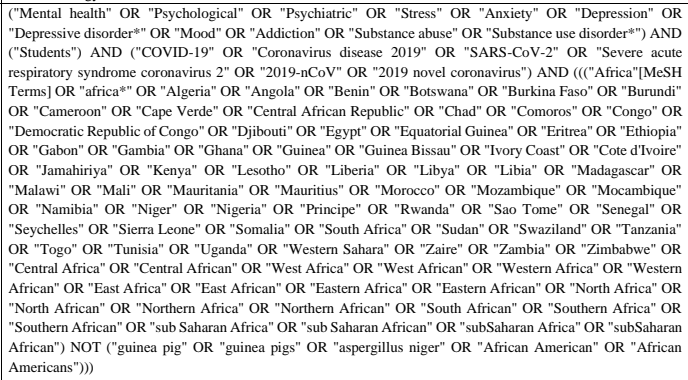 & $\begin{array}{l}\text { July 24, 2021 at 00:00 } \\
\text { GMT (Greenwich Mean } \\
\text { Time) } \\
\\
\end{array}$ \\
\hline EMBASE & 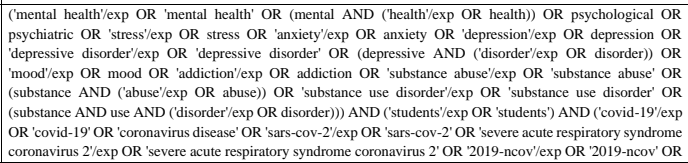 & $\begin{array}{l}\text { July } 24,2021 \text { at } 00: 15 \\
\text { GMT } \\
\end{array}$ \\
\hline
\end{tabular}

Figure 4: This is a caption 

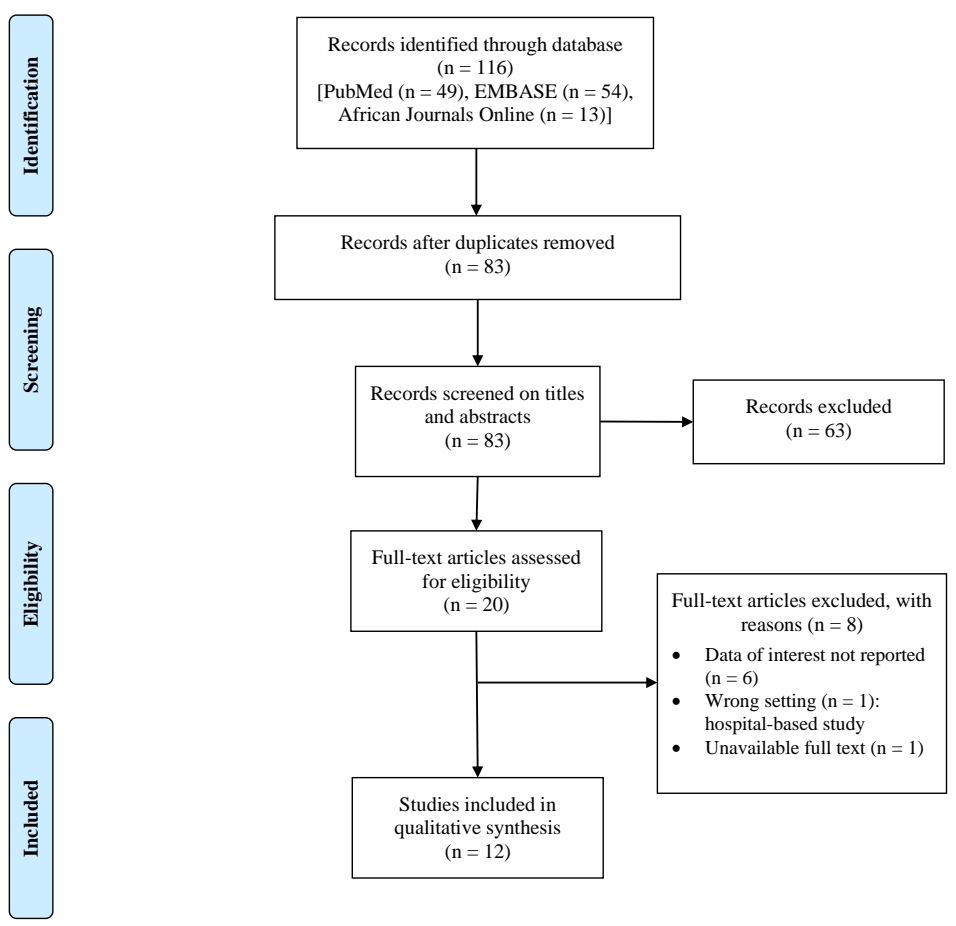

Figure 1: PRISMA Flow Chart of study selection

Figure 5: This is a caption

Authors' names: Diane Laure Meli Tiwa ${ }^{1,2}$, Dominic Leandry Angong Wouna ${ }^{1}$, Francky Teddy Endomba $^{3,4}$.

\section{Authors' affiliations}

1. Faculty of Medicine and Biomedical Sciences, University of Yaoundé I, Yaoundé

2. Annapolis Rheumatology at Owings Mills, Garrison MD USA

3. Research department, Medical Mind Association, Yaoundé, Cameroon

4. Psychiatry Internship Program, University of Bourgogne, 21000 Dijon, France

Corresponding author: Francky Teddy Endomba, Research Department, Medical Mind Association, Yaoundé, Cameroon.franckyteddyea@gmail.com

\section{Abstract}


Background: In addition to its direct mortality and morbidity, it has been reported that the coronavirus disease 2019 (COVID-19) can negatively impact psychological well-being of some populations. This systematic review aimed to summarize data pertaining to African universities students' mental health during this pandemic.

Methods: PubMed/MEDLINE, EMBASE and African Journals Online (AJOL) were systematically searched up to July 24, other to retrieve observational studies realized during the COVID-19 pandemic, and which assessed any mental health condition (notably depression, anxiety and stress) among students from African universities. Risk of bias appraisal of included studies was performed using the tool conceived by Hoy and colleagues. Results were presented as narrative, graphical and tabular summaries.

Results: A total of 12 studies were included for a sample size of 7,293 university students spread over seven countries. The overall quality of finally retained studies was moderate, and the Depression, Anxiety and Stress Scale 21-items (DASS-21) was used in 50\% of these studies. We found that the prevalence of depression varied from $21.3 \%$ to $78 \%$, with the frequency of severe depression prevalence ranged from $9.7 \%$ to $31.5 \%$. We found that the prevalence of all anxiety levels (at least mild) ranged from $27.1 \%$ to $64.5 \%$, with a frequency of severe anxiety going from $9.4 \%$ to $29.9 \%$. The prevalence of mild to severe stress varied between $22.2 \%$ and $47.8 \%$, with severe cases frequencies varying between $12.8 \%$ and $17.5 \%$. The most reported factors associated with depression/ anxiety/ stress were poor social support, low economic status and female gender.

Conclusion: Despite limited by the unrepresentativeness of some African regions, and the heterogeneity regarding the tool(s) used to assess outcomes of interest, this systematic review showed high rates of depression, anxiety and stress among African universities' students during the current COVID-19 pandemic.

Keywords: COVID-19, Mental health, Universities' Students, Africa

Other: This review received no funding and is registered in the prospective register of ongoing systematic reviews (PROSPERO). The registration number is CRD42021269772.

\section{Introduction}

\section{Rationale}

The first confirmed case of coronavirus disease 2019 (COVID-19) in Africa and sub-Saharan Africa were respectively announced on the February 14 and 27, 2020 in Egypt and Nigeria [1,2]. This was correspondingly two weeks after (January 30, 2020) and one month before (March 11, 2020) the categorization of the outbreak as a Public Health Emergency of International Concern (PHEIC) and as a pandemic [3]. According to the Africa branch of the Centre for Disease Control (Africa CDC), on August $1^{\text {st }}$ 2021, they were overall 170,187 COVID-19 related death, the most impacted region being the southern one [4]. Aside its well-recognized and highlighted human and economic consequences, this pandemic also affected the education sector, especially at the university level $[5,6]$.

In order to reduce the spread of the Severe Acute Respiratory Syndrome Coronavirus 2 (SARS-Cov-2), numerous governments, under the recommendations of national and international health institutions, have had to reorganize university programs [6,7]. These reorganizations notably involved the closure of universities (especially during lockdown periods), the suspension of face-to-face classes with or without the establishment of distance learning, and this also in Africa $[6,8,9]$. The reshaping of higher education in response to the COVID-19 pandemic had negative corollaries on universities students' wellbeing not only in terms of academic performances[5,10,11], but also regarding the psychological sphere [12-14]. Indeed, published studies reported high frequencies of mental health issues such as depression, anxiety and stress among universities' students during the current COVID-19 pandemic [14-16]. This not only due to the remodelling of university education negatively influencing their learning processes, but also as a consequence of stressors such as social distancing, loneliness, fear of infection regarding themselves or relatives, and the uncertainty of future $[12,13,16]$. Otherwise, all the currently existing studies summarizing data on this issue pertain to European, American or Asian settings [16-18]. 
Considering the unstable evolution of the COVID-19 pandemic worldwide, its reported impact on universities students' well-being amid other settings, and the lack of papers summarizing such information for Africa, we carried out this review.

\section{Objectives}

The present systematic review aimed to address the following question: What is the mental health status of African universities' students during the COVID-19 pandemic?

This question was built using the PICOS method [19]. In this approach, "P" refers to "Participants" (universities' students); "I" stands for "Intervention" (not applicable in our review); "C" for "Comparisons" (not applicable in our review); "O" for "Outcomes" (frequencies and associated factors of mental health issues among African universities' students during this COVID-19 pandemic time); and "S" represents "Studies" (observational studies).

This systematic review is reported in accordance with the checklist of the Preferred reporting items for systematic review and meta-analysis protocols (PRISMA) 2020 statement [20].

\section{Methods}

Eligibility criteria

The following criteria were needed for an article to be included in our review

1. Time frame: study realized during the coronavirus Disease 19 (COVID-19) outbreak,

2. Reports' characteristics: peer-reviewed articles without language restriction,

3. Design: Observational studies with more than 30 participants and thereby including cross-sectional, case-control and cohort studies (baseline data),

4. Participants and outcomes: articles reporting frequencies with or without associated/risk factors of mental health issues such as depression, anxiety and stress, among African universities' students.

We excluded unrelated or duplicated articles, as well as abstract-only papers in case of unavailability of information required for our review.

Information sources and search strategies: We applied a search strategy on PubMed/MEDLINE, Excerpta Medica Database (EMBASE) and African Journals Online (AJOL) by the July 24, 2021, respectively at 00:00, 00:15 and 00:30 (Greenwich Mean Time). To build the search strategies respectively dedicated to each of the three databases, we associated key-terms groups, with as first group the one related to mental health issues, as second the one related to "students", and as third the one pertaining to African regions and countries. For each group, synonyms and subtypes were joined using the Boolean operator "OR", and the three groups were linked by the Boolean operator "AND". For instance, regarding the group related to mental issues and the PubMed/MEDLINE database, we associated terms such as "Mental Health", "Psychological", "Depression", "Anxiety" and "Stress". Our search strategies are available in table 1. After applying our strategies in each database, the respective resulting lists were exported and further uploaded in Rayyan, a web and mobile app conceived for screening purpose in systematic reviews (https://rayyan.qcri.org/) [21]. In Rayyan, all the records (from the three databases) were joined as a same review project.

Selection process: We performed a two-steps selection process. First, based on the appraisal of titles and abstracts, and considering our eligibility criteria, two authors (FTE and WADL) independently selected articles. Discrepancies were resolved by a consensus or if necessary, by a third assessor (DLTM). After this first selection step, all relevant papers were exported from Rayyan in an appropriate file which later served to create a reference list of our selected articles, by using a reference software, notably Zotero (https://www.zotero.org/) [22]. The second step of the selection process involved to search for the full texts, and explore these fulltexts considering our eligibility criteria and especially our outcomes of interest. This step was independently performed by two authors (FTE and DLTM), with disagreements solved by a consensus or a third appraiser if necessary (WADL). 
Data collection process: The selection process was followed by data extraction. Indeed, we reviewed and collected data of interest from each article retained after titles, abstracts and full-texts screening. For this purpose, we used a predefined and pretested extraction tool, available in table 2 . The data extraction process was independently ensured by two authors (FTE and WADL), and a third one intervened if dissimilarities were not solvable through a consensus.

Data items: Throughout the data collection step, we looked at the following items

1. Bibliometric information: family name of the first author, year and journal of publication,

2. Study characteristics: study's country, study design, study period (and related COVID-19 stage if mentioned), study setting (one or more Faculties, one or more universities), sampling method, minimal sample size calculation, type of data collection process (paper and/or electronic version),

3. Participants' characteristics: subtype of university students (medical/ pharmacy/ health science students, etc.), mean or median age, age range, total sample size, sample size for males and females respectively,

4. Outcomes: mental health issues (depression, anxiety, stress, etc.) with the tool used to screen for each one, the cut-off scores potentially used, the reported frequency, as well as associated/risk factors if assessed.

Study risk of bias assessment: We based our risk of bias assessment on the tool developed by Hoy and colleagues [23]. This tool is made of 10 items addressing four domains of bias plus a summary risk of bias assessment. Included studies were classified according to their total score as low risk of bias $(8-10)$, moderate risk of bias $(6-7)$ and high risk of bias $(0-5)$.

Synthesis methods: We planned to present our results as narrative, graphical and tabular summaries, with respect to the following items

1. Information on the study selection process through the PRISMA model of study flow chart presentation,

2. Selected articles' individual characteristics with mental health issues assessed, displayed as narrative and tabular summary, and specifically including articles' bibliometric profiles, study and participants characteristics, tools/ cut-off scores/ frequencies/ factors regarding each studied mental health condition,

3. Methodological quality and risk of bias of each study, presented as narrative and tabular synopsis.

\section{Results}

Study selection: Our preliminary search through selected databases yielded a total of 116 articles. After removing duplicates, 83 remaining papers were reviewed based on their titles and abstracts, regarding our eligibility criteria. We excluded 63 articles and therefore retrieved and appraised the 20 lasting articles based on their full-texts and also considering our selection criteria. Finally, 12 articles [24-35] were systematically reviewed and qualitatively summarized. The PRISMA flow chart showing our study selection process is shown in figure 1.

Study characteristics: The sample size of the 12 included studies ranged from 103 to 2430 participants, with a total of 7,293 participants (2,741 males and 4,552 females, thus giving a female/male ratio of 1.66). The enrolled studies were conducted between March 17, and November 30, 2020. The 12 studies were realized in seven countries, namely Ethiopia $(\mathrm{n}=4)$, Egypt $(\mathrm{n}=2)$, Morocco $(\mathrm{n}=2)$, Liberia $(\mathrm{n}=1)$, Libya $(\mathrm{n}=1)$, Sudan $(\mathrm{n}=1)$ and Tunisia $(\mathrm{n}=1)$. Amid selected studies, 11 were reported as cross-sectional studies, and one as a transversal descriptive study [33]. Data were collected exclusively electronically (online surveys) in $9 / 12$ studies, only with a paper version form in one study[32], both with online and paper forms in one study[29], and through phone calls in one study [26]. Most of studies $(7 / 12)$ used a non-probabilistic sampling method, 4 studies reported a probabilistic sampling technique, and one article reported no details on the sampling method used. A minimal sample size was calculated in five studies [25,26,30,32,35]. Regarding studies' participants, the reported mean/median ages varied from 20 to 29 years, and four studies focused on medical/pharmacy students. Studies and participants' characteristics are summarized in table 3. 
Risk of bias in studies: Based on the 10-items questionnaire established by Hoy et al. [23], the overall quality of included studies is moderate. More precisely, we classified four studies as "low risk of bias", seven studies as "moderate risk of bias" and one study as "high risk of bias". The table 4 displays details of risk of bias assessment.

Results of individual studies and syntheses: Regarding the main outcome of our systematic review, psychological concerns varied across selected studies and especially included depression (depressive symptoms), anxiety and stress. More specifically, the most screened conditions were depression and anxiety (respectively in $9 / 12$ studies), and were followed by stress (8/12 studies). One research work assessed suicidal ideations, and another one studied non-specific psychological distress.

A diversity of scales/tools were used for the appraisal of these mental health outcomes. For depression, anxiety and stress, the most used screening tool was the Depression, Anxiety and Stress Scale 21-items (DASS-21). This tool was used in $6 / 12$ studies of our review $[26,28,31,32,34,35]$. All these studies used the followings as respective positive screening cut-off scores for depression, anxiety and stress: [?] 10, [?] 08 and [?] 15. These thresholds respectively corresponding to mild cases of depression, anxiety and stress. Regarding depression, two studies [29,30] used the Patient Health Questionnaire 9-items (PHQ-9) with a positive screening cut-off score of [?] 05 (mild cases) for one study and [?] 15 (moderately severe to severe depression) for the other, and one used the PHQ-8 (positive depression screening if [?] 10) [27]. Concerning anxiety, two studies $[29,30]$ used the Generalized Anxiety Disorder 7-item (GAD-7) scale with one study's threshold at 15 (severe anxiety) and the other's one at 05 (mild anxiety), and one used the Beck Anxiety Inventory (BAI) [24]. For the BAI, a score of $0-21$ was classified as low anxiety, 22-35 as moderate anxiety, and 36 or above as potentially concerning level of anxiety. To evaluate stress, two studies $[25,33]$ used the Perceived Stress Scale (PSS)-10 (Scores [?] 25 = high or pathological perceived stress), and the study that assessed non-specific psychological distress used the Kessler distress scale (K-6) [30].

Overall, eight studies reported a frequency for all depression degrees (at least mild). This one varied from $21.3 \%$ [26] to $78 \%$ [29]. Severe depression prevalence (from six studies) ranged from $9.7 \%$ [29,31] to $31.5 \%$ [34]. Eight studies reported a prevalence of all anxiety levels (at least mild) ranging from $27.1 \%$ [26] to $64.5 \%$ [29], with a frequency of severe anxiety (7/12 studies concerned) going from $9.4 \%$ [24] to 29.9\% [34]. From six of our 12 included studies, the prevalence of mild to severe stress varied between $22.2 \%$ [32] and $47.8 \%$ [31], with severe cases (4/12 studies synthetized) frequencies varying between $12.8 \%$ [35] and 17.5\% [34]. The two studies that used the Perceived Stress Scale (PSS)-10 respectively reported frequencies of pathological perceived stress at 35.9\% [25] and 49\% [33]. Others negative mental health outcomes assessed by some of the selected studies included suicidal ideations [29] and non-specific psychological distress [30], respectively found at $22.7 \%$ and $69 \%$. The summarized findings encompassing frequencies of mental health issues as well as risk/associated factors assessed and reported by included studies, are available in table 3 . The most reported factors associated with depression/ anxiety/ stress were poor social support, low economic status and female gender.

\section{Discussion}

General interpretation of the results in the context of other evidence

This systematic review aimed to evaluate the mental health issues related to the current pandemic among African universities' students. Overall, we summarized data pertaining to 12 studies and involving 7,293 students living in seven different countries. Six studies concerned sub-Saharan Africa, with four in Ethiopia. We found that approximately 2-8/10 and 1-3/10 students had respectively depression and severe depression, that nearly 3-6/10 and 1-3/10 suffered from anxiety and severe anxiety, and that around 2-5/10 and 1-2/10 students were stressed and severely stressed.

Compared to data on African universities students' mental health before the pandemic, we found relatively higher rates of mental health issues. For example, a review assessing the prevalence of depression among universities students in low and middle income countries (LMICs) and that included three studies in Africa, found a depression prevalence of $34.2 \%$ for African students [36]. On another side, while focusing on the 
COVID-19 pandemic mental health impact amid the general population in Africa during this pandemic, there is a scarcity of review articles [37]. Nevertheless, a systematic review of the prevalence of anxiety among the general population during the COVID-19 pandemic found that the prevalence in Africa was $61.8 \%$ (95\% CI, $57 \%-66.4 \%$ ) [38], which is higher than the one we found. This difference might be due to the role played by populations type such as health care workers (especially doctors and nurses) in the increase of these frequencies $[39,40]$.

We generally found equal or higher frequencies of psychological concerns than studies reporting the same outcomes in others parts of the word. For instance, Li et al. in a meta-analysis of 706,415 college students showed that the prevalence of depression was 39\% (95\% CI: 27-51\%) and that of anxiety was 36\% (95\% CI: 26-46\%) [41]. In the same way, Deng and colleagues while summarizing data of eighty-nine studies and 1,441,828 higher education students during the COVID-19 pandemic, found that the pooled prevalence of depressive symptoms and anxiety symptoms was $34 \%$ and $32 \%$ respectively [42]. More specifically, they reported depression and anxiety pooled prevalence of $55 \%$ and $74 \%$ for the United States of America, and $24 \%$ and $23 \%$ for China [42]. Regarding China, a systematic review involving 1,292,811 universities students displayed pooled depressive symptoms prevalence of $26 \%$ [16]. Explanatory factors of the dissimilarities between our findings and the one reported in previous published review might be the difference regarding sample size, but also the disparity pertaining to the tools used as well as related cut-off scores. Looking for instance at this last reason, Deng et al. in their review reported that most of studies used the PHQ-9 for depression and the GAD-7 for anxiety [42], while in our review most of studies used the DASS-21 for both. Otherwise, the higher prevalence reported by previous papers for some world regions such as America[42], might be linked to a greater COVID-19 morbidity and mortality when compared to Africa [43]. Concerning factors associated with negative mental health consequences among universities' students, other reports in literature highlighted that the pandemic had a more pronounced effect on female students [44,45]. This is also the case for low socio-economic status [45].

\section{Limitations of the review}

The findings of our review should be interpretated with caution due to parameters such as the small amount of included studies and their moderate quality, the unrepresentativeness of some African regions, as well as the inconsistency regarding the tool(s) used to assess mental health concerns of interest. Nevertheless, to our knowledge, this review is the first one specifically focused on African universities students' mental health during this COVID-19 pandemic.

\section{Conclusion (Implications of the results for practice, policy and future research)}

This systematic review showing high rates of depression, anxiety and stress among African universities' students during the current COVID-19 pandemic, might justify the need to reinforce psychological support (face-to-face or at least in remote mode) amid this subpopulation. This especially for students with poor social support and low economic status. While looking at our findings, further longitudinal studies might be interesting since they would provide how these psychological concerns evolve with pandemic. Also, it would be of interest to realize studies assessing the relationship between these mental health outcomes and academic performances.

\section{What is already known on this topic}

Studies published amid settings in Asia, Europe and Americas, where the morbidity and the mortality of COVID-19 is higher than in Africa, reported high frequencies of negative mental health repercussions.

\section{What this study adds}

There is a scarcity of studies assessing psychological well-being of universities' students in Africa during this COVID-19 pandemic, especially for regions such as Central Africa, West Africa and Southern Africa.

There are high frequencies of depression, anxiety and stress among African universities' students during this pandemic, with approximately similar rates than in areas with higher COVID-19 morbidity and mortality. 


\section{Other information}

Registration and protocol: The protocol of this review was not published in a peer-review journal, and review is registered in the prospective register of ongoing systematic reviews (PROSPERO). The registration number is CRD42021269772.

Support: This review received no financial support.

Competing interests: The authors declared no competing interests.

Availability of data, code and other materials: Our template form for data collection is available in table 2.

Authors' contributions

FTE: Study conception, protocol registration, article selection, data extraction and synthesis, manuscript drafting, approval of the final article version

DLAW: Article selection, data extraction and synthesis, manuscript correction, approval of the final article version

DLTM: Article selection, data extraction and synthesis, manuscript correction, approval of the final article version

\section{List of tables and figures}

Table 1: Search strategy used, adapted to each of our databases

Table 2: Data extraction form

Table 3: Qualitative synthesis of studies included in the systematic review

Table 4: Methodological quality and risk of bias of included studies (according to the tool developed by Hoy et al.)

Figure 1: PRISMA Flow Chart of study selection

\section{References}

1. Africa CDC. Africa Identifies First Case of Coronavirus Disease: Statement by the Director of Africa CDC. https://africacdc.org/news/africa-identifies-first-case-of-coronavirus-disease-statement-by-thedirector-of-africa-cdc/. Accessed 3 August 2021

2. Nigeria Centre for Disease Control. First case of corona virus disease confirmed in Nigeria. https://ncdc.gov.ng/news/227/first-case-of-corona-virus-disease-confirmed-in-nigeria. Accessed 3 August 2021

3. World Health Organization. Timeline: WHO's COVID-19 response. https://www.who.int/emergencies/diseases/novel-coronavirus-2019/interactive-timeline. $\quad$ Accessed 3 August 2021

4. Africa CDC. Latest updates on the COVID-19 crisis from Africa CDC. https://africacdc.org/covid-19/. Accessed 3 August 2021

5. Burki TK. COVID-19: consequences for higher education. Lancet Oncol. 2020;21(6):758.

6. Omanga D. Covid-19, Technology, and Higher Education in Sub-Saharan Africa. https://items.ssrc.org/covid-19-and-the-social-sciences/mediated-crisis/covid-19-technology-and-highereducation-in-sub-saharan-africa/. Accessed 3 August 2021

7. Tamrat W, Teferra D. COVID-19 Threat to Higher Education: Africa's Challenges, Responses, and Apprehensions. International Higher Education. https://www.academia.edu/42926809/COVID_19_Threat_to_Higher_Education_Africa_s_Challenges_Responses_and_Apprehensions. Accessed 5 A August 2021 
8. Paravattil B, Zolezzi M, Carr AS, Al-Moslih A. Reshaping experiential education within Qatar University's Health Programs during the COVID-19 pandemic. Qatar Med J. 2021;2021:9.

9. Rajab MH, Gazal AM, Alkattan K. Challenges to Online Medical Education During the COVID-19 Pandemic. Cureus. 2020;12(7):e8966.

10. Gonzalez T, de la Rubia MA, Hincz KP, Comas-Lopez M, Subirats L, Fort S, et al. Influence of COVID-19 confinement on students' performance in higher education. PLoS One. 2020;15(10):e0239490.

11. Gore J, Fray L, Miller A, Harris J, Taggart W. The impact of COVID-19 on student learning in New South Wales primary schools: an empirical study. Aust Educ Res. 2021;1-33.

12. Sahu P. Closure of Universities Due to Coronavirus Disease 2019 (COVID-19): Impact on Education and Mental Health of Students and Academic Staff. Cureus. 2020;12(4):e7541.

13. Wathelet M, Duhem S, Vaiva G, Baubet T, Habran E, Veerapa E, et al. Factors Associated With Mental Health Disorders Among University Students in France Confined During the COVID-19 Pandemic. JAMA Netw Open. 2020;3(10):e2025591.

14. Nurunnabi M, Almusharraf N, Aldeghaither D. Mental health and well-being during the COVID-19 pandemic in higher education: Evidence from G20 countries. J Public Health Res. 2021;9(Suppl 1):2010.

15. Ochnik D, Rogowska AM, Kuśnierz C, Jakubiak M, Schütz A, Held MJ, et al. A Comparison of Depression and Anxiety among University Students in Nine Countries during the COVID-19 Pandemic. J Clin Med. 2021;10(13):2882.

16. Luo W, Zhong B-L, Chiu HF-K. Prevalence of depressive symptoms among Chinese university students amid the COVID-19 pandemic: a systematic review and meta-analysis. Epidemiol Psychiatr Sci. 2021;30:e31.

17. López-Valenciano A, Suárez-Iglesias D, Sanchez-Lastra MA, Ayán C. Impact of COVID-19 Pandemic on University Students' Physical Activity Levels: An Early Systematic Review. Front Psychol. 2020;11:624567.

18. Lasheras I, Gracia-García P, Lipnicki DM, Bueno-Notivol J, López-Antón R, de la Cámara C, et al. Prevalence of Anxiety in Medical Students during the COVID-19 Pandemic: A Rapid Systematic Review with Meta-Analysis. Int J Environ Res Public Health. 2020;17(18):E6603.

19. Methley AM, Campbell S, Chew-Graham C, McNally R, Cheraghi-Sohi S. PICO, PICOS and SPIDER: a comparison study of specificity and sensitivity in three search tools for qualitative systematic reviews. BMC Health Serv Res. 2014;14:579.

20. Page MJ, McKenzie JE, Bossuyt PM, Boutron I, Hoffmann TC, Mulrow CD, et al. The PRISMA 2020 statement: an updated guideline for reporting systematic reviews. BMJ. 2021;372:n71.

21. Ouzzani M, Hammady H, Fedorowicz Z, Elmagarmid A. Rayyan-a web and mobile app for systematic reviews. Syst Rev. 2016;5(1):210.

22. Vanhecke TE. Zotero. J Med Libr Assoc. 2008;96(3):275-6.

23. Hoy D, Brooks P, Woolf A, Blyth F, March L, Bain C, et al. Assessing risk of bias in prevalence studies: modification of an existing tool and evidence of interrater agreement. J Clin Epidemiol. 2012;65(9):934-9.

24. Abas IMY, Alejail IIEM, Ali SM. Anxiety among the Sudanese university students during the initial stage of COVID-19 pandemic. Heliyon. 2021;7(3):e06300.

25. Awoke M, Mamo G, Abdu S, Terefe B. Perceived Stress and Coping Strategies Among Undergraduate Health Science Students of Jimma University Amid the COVID-19 Outbreak: Online Cross-Sectional Survey. Front. Psychol. 2021;12:639955.

26. Aylie NS, Mekonen MA, Mekuria RM. The Psychological Impacts of COVID-19 Pandemic Among University Students in Bench-Sheko Zone, South-west Ethiopia: A Community-based Cross-sectional Study. 
Psychology Research and Behavior Management. 2020:13 813-821.

27. Davis EJ, Amorim G, Dahn B, Moon TD. Perceived ability to comply with national COVID-19 mitigation strategies and their impact on household finances, food security, and mental well-being of medical and pharmacy students in Liberia. PLOS ONE. 2021;16(7):e0254446.

28. El-Monshed AH, El-Adl AA, Ali AS, Loutfy A. University students under lockdown, the psychosocial effects and coping strategies during COVID-19 pandemic: A cross sectional study in Egypt. J Am Coll Health. 2021;1-12.

29. Elhadi M, Buzreg A, Bouhuwaish A, Khaled A, Alhadi A, Msherghi A, et al. Psychological Impact of the Civil War and COVID-19 on Libyan Medical Students: A Cross-Sectional Study. Front Psychol. 2020;11:570435.

30. Essangri H, Sabir M, Benkabbou A, Majbar MA, Amrani L, Ghannam A, et al. Predictive Factors for Impaired Mental Health among Medical Students during the Early Stage of the COVID-19 Pandemic in Morocco. Am J Trop Med Hyg. 2021;104(1):95-102.

31. Ghazawy ER, Ewis AA, Mahfouz EM, Khalil DM, Arafa A, Mohammed Z, et al. Psychological impacts of COVID-19 pandemic on the university students in Egypt. Health Promot Int. 2020;daaa147.

32. Mekonen EG, Workneh BS, Ali MS, Muluneh NY. The Psychological Impact of COVID-19 Pandemic on Graduating Class Students at the University of Gondar, Northwest Ethiopia. Psychol Res Behav Manag. 2021;14:109-22.

33. Rahali K, Abidli Z, Khohmimidi A, Elhamzaoui -Mohamed, Seghiri R, Jabari K, et al. Ibn Tofail's University students' satisfaction evaluation towards distance learning and its impacts on the students' mental health during the Covid 19 Confinement. Bangladesh J Med Sci. 2020;51-S 57.

34. Saguem BN, Nakhli J, Romdhane I, Nasr SB. Predictors of sleep quality in medical students during COVID-19 confinement. L'Encephale. 2021;S0013-7006(21)00074-9.

35. Simegn W, Dagnew B, Yeshaw Y, Yitayih S, Woldegerima B, Dagne H. Depression, anxiety, stress and their associated factors among Ethiopian University students during an early stage of COVID-19 pandemic: An online-based cross-sectional survey. PLOS ONE. 2021;16(5):e0251670.

36. Akhtar P, Ma L, Waqas A, Naveed S, Li Y, Rahman A, et al. Prevalence of depression among university students in low and middle income countries (LMICs): a systematic review and meta-analysis. J Affective Disord. 2020;274:911-9.

37. Kar SK, Oyetunji TP, Prakash AJ, Ogunmola OA, Tripathy S, Lawal MM, et al. Mental health research in the lower-middle-income countries of Africa and Asia during the COVID-19 pandemic: A scoping review. Neurol Psychiatry Brain Res. 2020;38:54-64.

38. Pashazadeh Kan F, Raoofi S, Rafiei S, Khani S, Hosseinifard H, Tajik F, et al. A systematic review of the prevalence of anxiety among the general population during the COVID-19 pandemic. J Affective Disord. 2021;293:391-8.

39. Chigwedere OC, Sadath A, Kabir Z, Arensman E. The Impact of Epidemics and Pandemics on the Mental Health of Healthcare Workers: A Systematic Review. Int J Environ Res Public Health. 2021;18(13):6695.

40. Quadri NS, Sultan A, Ali SI, Yousif M, Moussa A, Fawzy Abdo E, et al. COVID-19 in Africa: Survey Analysis of Impact on Health-Care Workers. Am J Trop Med Hyg. 2021;tpmd201478.

41. Li Y, Wang A, Wu Y, Han N, Huang H. Impact of the COVID-19 Pandemic on the Mental Health of College Students: A Systematic Review and Meta-Analysis. Front Psychol. 2021;12:669119.

42. Deng J, Zhou F, Hou W, Silver Z, Wong CY, Chang O, et al. The prevalence of depressive symptoms, anxiety symptoms and sleep disturbance in higher education students during the COVID-19 pandemic: A 
systematic review and meta-analysis. Psychiatry Research. 2021;301:113863.

43. World Health Organization. WHO Coronavirus (COVID-19) Dashboard. https://covid19.who.int. Accessed 3 August 2021

44. Prowse R, Sherratt F, Abizaid A, Gabrys RL, Hellemans KGC, Patterson ZR, et al. Coping With the COVID-19 Pandemic: Examining Gender Differences in Stress and Mental Health Among University Students. Front Psychiatry. 2021;12:650759.

45. Browning MHEM, Larson LR, Sharaievska I, Rigolon A, McAnirlin O, Mullenbach L, et al. Psychological impacts from COVID-19 among university students: Risk factors across seven states in the United States. PLoS One. 2021;16(1):e0245327. 